\title{
Fabrication of the Composite Ferrite Electromagnetic Wave Absorber
}

\author{
H. UENO, T. YASUYOSHI, and S. YOSHIKADO
}

Department of Electronics, Doshisha University, Kyotanabe 610-03, Japan

\begin{abstract}
We have developed the composite metal-backed single layered electromagnetic absorber of spinel-type Ni-Znferrite and hexagonal Ba-ferrite which operates in the frequency region between 1 and $4 \mathrm{GHz}$. Temperature dependences of the complex permittivity, complex permeability, and return loss are measured in the range between the room temperature and $160{ }^{\circ} \mathrm{C}$. The composite ferrite with a suitable thickness has the higher absorption frequency range than that of the spinel ferrite ( $\mathrm{Ni}-\mathrm{Zn}$ ferrite) absorber and the center absorption frequency can be changed by changing the mixing ratio. Composite ferrite showed the excellent temperature independency up to about $100^{\circ} \mathrm{C}$.
\end{abstract}

\section{INTRODUCTION}

There are many needs concerning to the utility of electromagnetic wave. It is necessary that electromagnetic wave absorbers (E.W.A.) with both wide absorbing range and wide selectivity for absorbing frequency are required. If E.W.A. is composed of loss dielectric materials, it is in need of thickness of 100 centimeter. So we used metalbacked single layered absorber as the thin ferrite absorbing wall. In the field of electromagnetic circumstance technique, electromagnetic wave absorber using ferrite (spinel-structure-type ferrites) plates are widely applied [1-6]. In general, natural magnetic resonance phenomenon occurs in ferrite materials and magnetic loss at resonance frequency is very large. The frequency dependence of complex permeability and permittivity of spinel-type and hexagonal ferrites is similar to the ideal absorbing characteristic in the limited frequency range.

The working frequency of E.W.A. using spinel-type ferrites is limited up to about $1 \mathrm{GHz}$, though the band width of absorbing is wide. On the other hand, the working frequency using hexagonal ferrites is higher than that for spinel-type ferrites, though the band width of absorbing is narrow [5]. We tried to fabricate the composite E.W.A., which operate in the frequency range between $1 \mathrm{GHz}$ and about $4 \mathrm{GHz}$, using spinel-structure-type ferrites as a host material. We also have evaluated the temperature dependence of the reflection characteristics between the room temperature and $200^{\circ} \mathrm{C}$. There has been no study on the temperature dependence of the reflection characteristics.

\section{EXPERIMENTAL}

Starting materials for preparation of spinel-type $\mathrm{Ni}-\mathrm{Zn}$ ferrite ( $\mathrm{NZ11}: \mathrm{Ni}_{05} \mathrm{Zn}_{05} \mathrm{Fe}_{4} \mathrm{O}_{8}$ ) were mixture of $\mathrm{NiO}, \mathrm{Zn0}$, and $\mathrm{Fe}_{2} \mathrm{O}_{3}$ powders of $99.99 \%$ purity. Starting materials for preparation of hexagonal Ba-ferrite (NC13:BaO$2\left[\mathrm{Ni}_{025} \mathrm{Co}_{0.75} \mathrm{O}\right] \cdot 7.8 \mathrm{Fe}_{2} \mathrm{O}_{3}$ ) were mixture of $\mathrm{BaCO}_{3}, \mathrm{NiO}$, $\mathrm{CoO}$, and $\mathrm{Fe}_{2} \mathrm{O}_{3}$ powders of $99.99 \%$ purity. For each ferrite, these were wet-mixed using ethyl alcohol. The mixture powder was pressed at $320 \mathrm{MPa} / \mathrm{cm}^{2}$ to disk with a diameter of $20 \mathrm{~mm}$ and then presintered at $800^{\circ} \mathrm{C}$ for $5 \mathrm{~h}$ for $\mathrm{NZ11}$ and at $900^{\circ} \mathrm{C}$ for $5 \mathrm{~h}$ for $\mathrm{NC13}$. After natural cooling, the disk was ground to powder and again pressed at $\mathbf{3 2 0}$ $\mathrm{MPa} / \mathrm{cm}^{2}$ formed to the disc. The final sintering of the disk specimens was performed at $1000^{\circ} \mathrm{C}$ for $10 \mathrm{~h}$ for $\mathrm{NZ1} 11$ and at $1200^{\circ} \mathrm{C}$ for $10 \mathrm{~h}$ for $\mathrm{NC13}$ by the hot-pressing method. After natural cooling, the disk was ground to powder. Composite samples were made by mixing the ferrite powder of $\mathrm{NZ1} 1$ and $\mathrm{NC} 13$ with mixing ratio (wt\%) shown in Table 1. The mixture powder was pressed at 320 $\mathrm{MPa} / \mathrm{cm}^{2}$ to disk with a diameter of $20 \mathrm{~mm}$ and finally sintered at $1000{ }^{\circ} \mathrm{C}$ for $2 \mathrm{~h}$. The structures of composite ferrites were analyzed by an $\mathrm{X}$-ray diffraction $(\mathrm{XRD})$ pattern (Philips, MPD1880).

Disks were processed to troidal core-type samples with outer and inner diameters of $7 \mathrm{~mm}$ and $3 \mathrm{~mm}$ and thickness of $6 \mathrm{~mm}$, respectively. Reflection coefficients of the coaxial cell loaded with the sample shorted by the shorting plate and opened by the open terminator were measured in the frequency region between $1 \mathrm{MHz}$ to $6 \mathrm{GHz}$ by an $\mathrm{HP}$ $8752 \mathrm{C}$ vector network analyzer. Both the complex permittivities and the complex permeabilities were calculated from the measured reflection coefficients using

Table I Mixing ratios of $\mathrm{N}-\mathrm{Zn}$-ferrite and Ba-ferrite (wt\%).

\begin{tabular}{ccc}
\hline Sample & $\begin{array}{c}\text { Mixing ratio } \\
\text { NZ11(wt\%) }\end{array}$ & NC13(wt\%) \\
\hline Ni-Zn-ferrite & 100 & 0 \\
ZC91 & 90 & 10 \\
ZC82 & 80 & 20 \\
ZC64 & 60 & 40 \\
ZC46 & 40 & 60 \\
ZC28 & 20 & 80 \\
Ba-ferrite & 0 & 100 \\
\hline
\end{tabular}


an open-short method.

Temperature dependence of the complex reflection coefficient was measured in the temperature range between the room temperature $\left(25^{\circ} \mathrm{C}\right)$ and $160{ }^{\circ} \mathrm{C}$ in the $\mathrm{N}_{2}$ gas atmosphere.

\section{RESULTS AND DISCUSSION}

X-ray diffraction patterns of the composite samples, Ni$\mathrm{Zn}$-ferrite, and Ba-ferrite are shown in Fig.1. For the composite samples, both ferrites were detected. Peaks of Ba-ferrite increased with increasing the content. It is conjectured that solid-solution of $\mathrm{Ni}-\mathrm{Zn}$-ferrite and $\mathrm{Ba}$ ferrite was not formed. However, $\mathrm{Ba}^{2+}$ ions may diffuse into $\mathrm{Ni}-\mathrm{Zn}$-ferrite.

Figure 2 shows the frequency dependence of (a) the real part $\mu^{\prime}$ and (b) imaginary part $\mu^{\prime \prime}$ of the relative complex permeability $\mu\left(=\mu^{\prime}-i \mu^{\prime \prime}\right)$ of composite ferrites at 25 ${ }^{\circ} \mathrm{C}$. The real part of the relative complex permittivity $\varepsilon\left(=\varepsilon^{\prime}-i \varepsilon^{\prime \prime}\right)$ of the composite ferrites was frequency independent in the measuring frequency range with value of about 12 . The $\mu^{\prime}$ decreased in the frequency range up to $1 \mathrm{GHz}$ and increased in the frequency range above $1 \mathrm{GHz}$ with increasing the content of Ba-ferrite. The $\mu^{\prime}$ for Baferrite was nearly constant (about $1 \sim 4$ ) in the measuring frequency range. The $\mu^{\mathrm{n}}$ decreased with increasing the

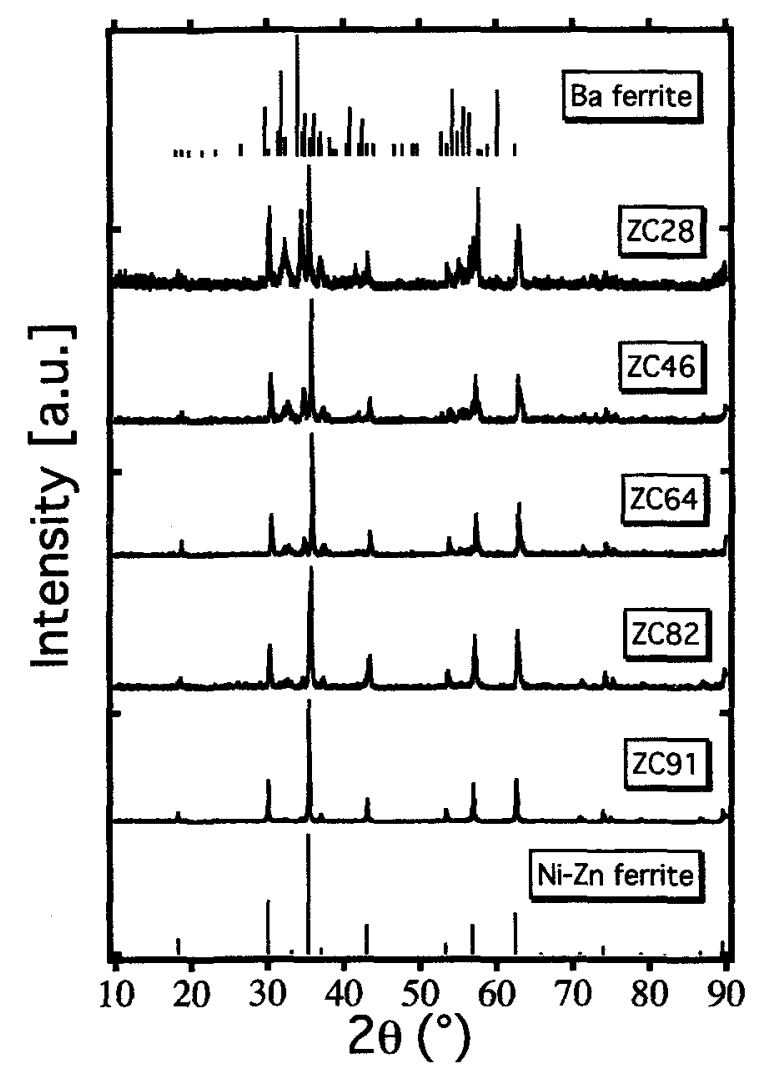

Fig.1. X-ray diffraction patterns of the composite samples, $\mathrm{Ni}-\mathrm{Zn}$-ferrite, and Ba-feriite. content of Ba-ferrite.

In the case of a metal-backed single layered absorber, the normalized input impedance $z$ at the front end of the absorber is expressed as shown [4]:

$$
z=\left(\frac{\mu}{\varepsilon}\right)^{\frac{1}{2}} \tanh \left\{i \frac{2 \pi}{\lambda}(\varepsilon \cdot \mu)^{\frac{1}{2}} d\right\},
$$

where $\lambda$ is the wavelength of the electromagnetic wave and $d$ is the thickness of the absorber. The complex reflection coefficient $\Gamma$ is expressed as follow:

$$
\Gamma=\frac{z-1}{z+1} .
$$

Return loss $R$ is expressed by

$$
R=20 \log _{10}|\Gamma| \text {. }
$$

For the no reflection condition, $z=1+i 0$. At the absorbing center frequency $f_{0}$, the following relation is obtained by (1):

$$
\begin{aligned}
& \mu^{\prime} \cong \frac{\varepsilon^{\prime}}{3} . \\
& \mu^{\prime \prime} \cong \frac{\lambda}{2 \pi d}
\end{aligned}
$$

When (4) is applied to the results shown in Fig.2 (a), $f_{0}$ corresponds to the frequency at where $\varepsilon^{\prime}$ is about 4 . These relationship is important to design materials for E.W.A.

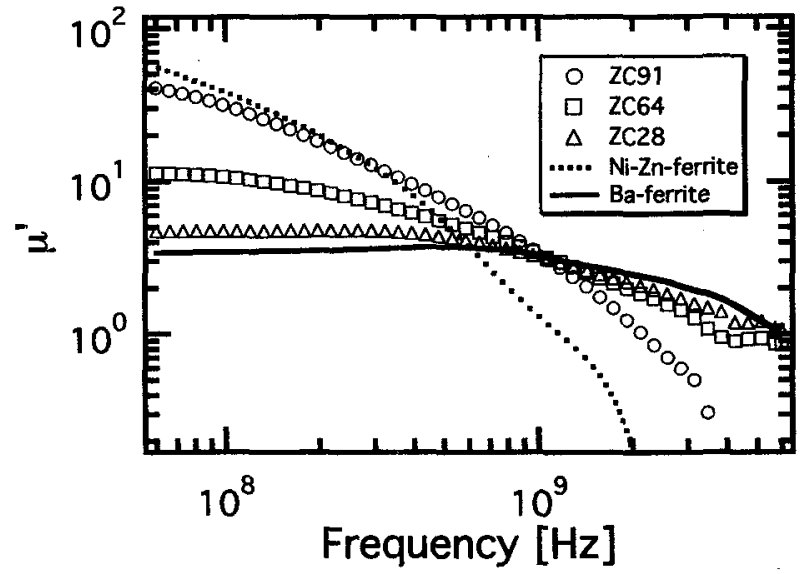

(a) real part

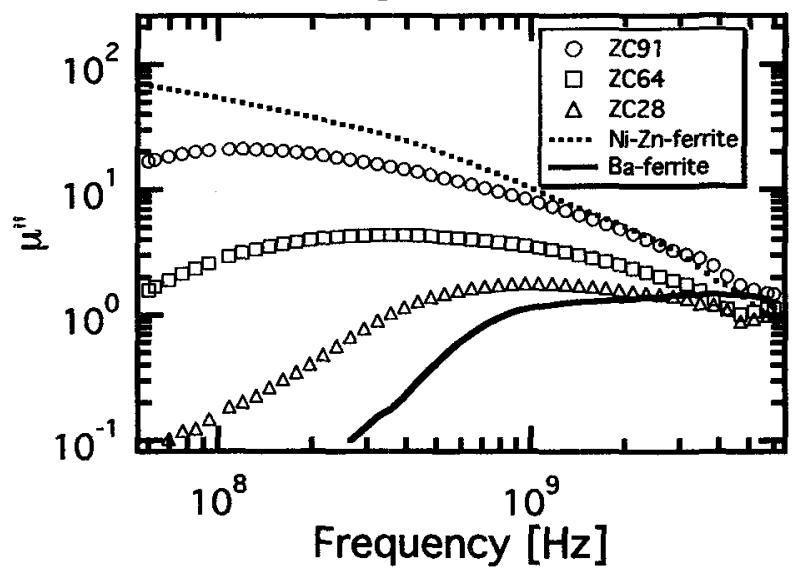

(b) imaginary part

Fig. 2 Frequrncy dependence of the relative complex permeability of composite ferites. 


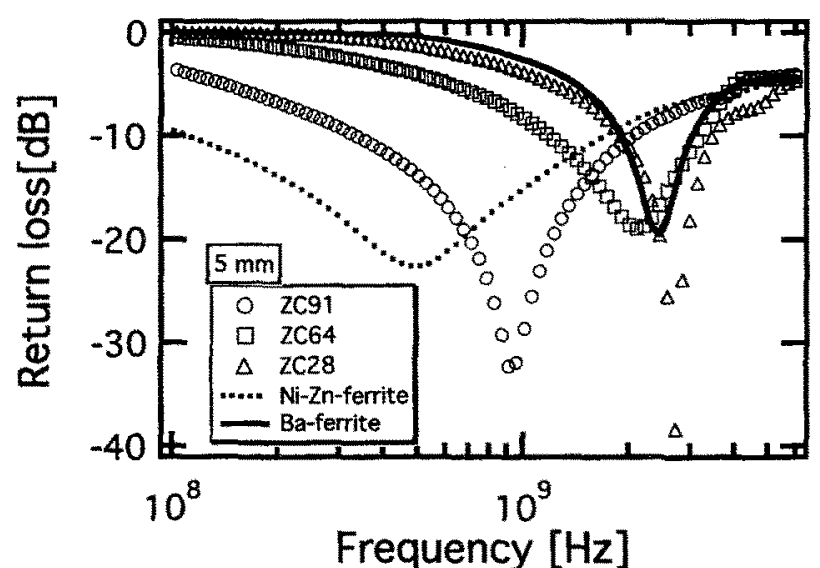

(a) $5 \mathrm{~mm}$

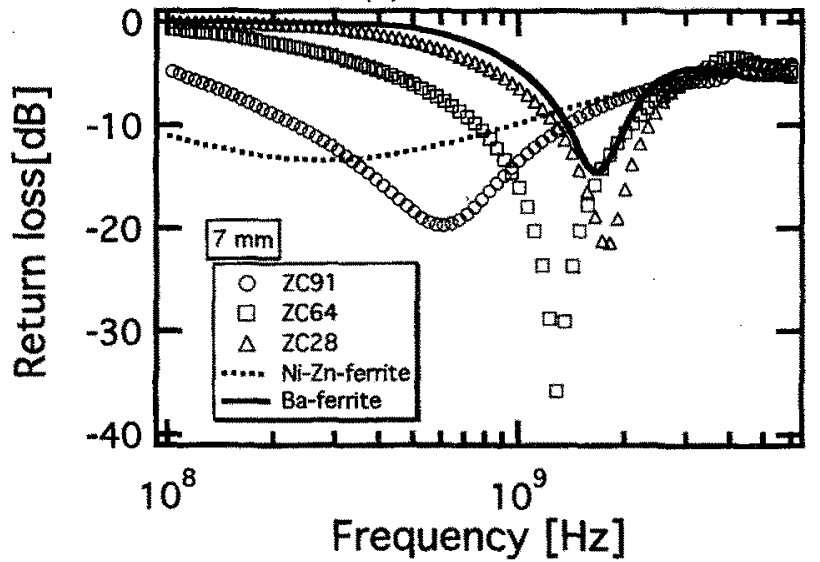

(b) $7 \mathrm{~mm}$

Fig. 3 Frequency dependence of the return loss for samples with thicknesses of 5 and $7 \mathrm{~mm}$ calculated using (1) to (3).

with desired reflection characteristics.

Figure 3 shows the frequency dependence of the return loss for samples with thickness of 5 and $7 \mathrm{~mm}$ at $25^{\circ} \mathrm{C}$ calculated from measured values of $\varepsilon$ and $\mu$ using (1) to (3). The $f_{0}$ for composite samples was shifted to the higher frequency region than that for NZ11 with the same thickness and the absorbing band width is relatively wide, because (4) is satisfied in this frequency region.

Figure 4 shows the temperature dependence of the return loss for ZC64 with thickness of $7 \mathrm{~mm}$ calculated from measured values of $\varepsilon$ and $\mu$ using (1) to (3). Figure 5 shows the temperature dependence of the normalized 20 $\mathrm{dB}$ bandwidth and the absorbing center frequency $f_{0}$ for ZC64 with thickness of $7 \mathrm{~mm}$ between the room temperature and $120^{\circ} \mathrm{C}$. The normalized $20 \mathrm{~dB}$ bandwidth is defined as $\Delta f / f_{0}$ where $\Delta f$ is the bandwidth of absorbing frequency at which the return loss is less than $-20 \mathrm{~dB}$. Both values were nearly temperature independent up to about $100^{\circ} \mathrm{C}$.

\section{CONCLUSIONS}

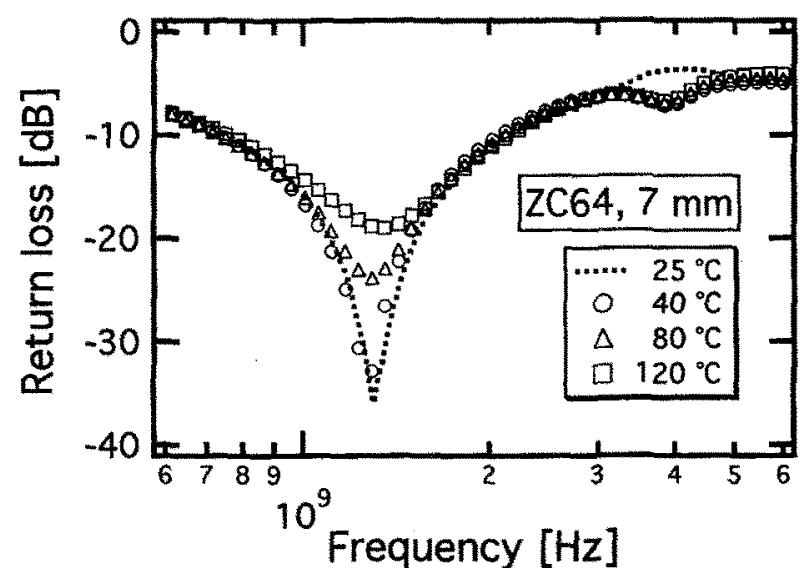

Fig. 4 Frequrncy dependence of the return loss for ZC64 with thickness of $7 \mathrm{~mm}$ at several temperatures.

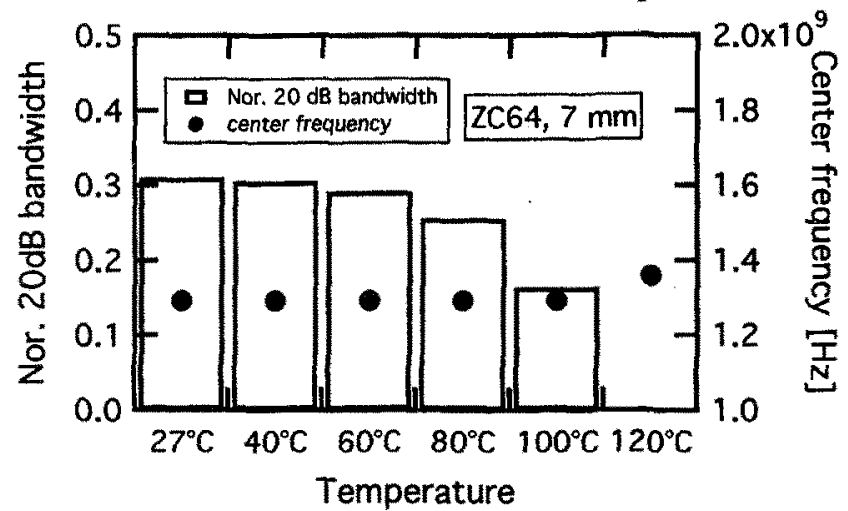

Fig. 5 Temperature dependence of the normalized $20 \mathrm{~dB}$ bandwidth and absorbing center frequency for ZC64 with thickness of $7 \mathrm{~mm}$.

Metal-backed single layered electromagnetic absorber made with the composite ferrites with a suitable thickness $(5 \sim 7 \mathrm{~mm})$ has the higher absorbing frequency range than that of the spinel-type ferrite absorber and the absorbing center frequency can be changed by changing the mixing ratio of hexagonal ferrite. Composite ferrite showed the excellent temperature independency up to about $100^{\circ} \mathrm{C}$.

\section{REFERENCES}

[1] K.Hatakeyama and T.Inui, IEEE Trans. Magn., vol.MAG-20[5], pp. 1261-1263, 1984.

[2] V.K.Varadan, V.V.Varadan, Y.Ma, and W.F.Hall, IEEE Trans. Microwave Theory and Tech, vol.MTT-34[2], 251258, 1986.

[3] K-y.Kim, W-s.Kim, and S-y.Kim, IEEE Trans. Magn., vol.MAG-29[3], pp. 2134-2138, 1993.

[4] J.Y.Shin and J.H.Oh, IEEE Trans. Magn., vol.MAG29[6], pp. 3437-3439, 1993.

[5] J.L.Wallace, IEEE Trans. Magn., vol.MAG-29[6], pp. 4209-4214, 1993.

[6] N.Dishovski, IEEE Trans. Magn., vol.MAG-30[2], pp. 969-971, 1994. 